\title{
Assessment of the safe evacuation of people walking through flooding staircases based on numerical simulation*
}

\author{
Wei-yun SHAO ${ }^{\dagger 1}$, Li-jie JIANG ${ }^{2,4}$, Lei FANG ${ }^{\dagger 1}$, David Z. ZHU ${ }^{3}$, Zhi-lin SUN ${ }^{4}$ \\ $\left({ }^{1}\right.$ College of Civil Engineering and Architecture, Zhejiang University, Hangzhou 310058, China) \\ ( ${ }^{2}$ Zhejiang Design Institute of Water Conservancy \& Hydroelectric Power, Hangzhou 310002, China) \\ $\left({ }^{3}\right.$ Department of Civil and Environmental Engineering, University of Alberta, Edmonton AB, T6G 2W2, Canada) \\ ( ${ }^{4}$ Department of Ocean Science and Engineering, Zhejiang University, Hangzhou 310058, China) \\ †E-mail: shaowy@zju.edu.cn; fanglei1999@126.com \\ Received May 28, 2014; Revision accepted Dec. 17, 2014; Crosschecked Jan. 22, 2015
}

\begin{abstract}
A numerical model was developed to evaluate the possibility of people walking in a flooding flow on a staircase with rest platforms. Commercial software was used and validated by experimental data for flows on staircases and stepped spillways. The effects of the rest platform, the staircase slope, and the staircase pattern on the flooding flow characteristics are discussed. A comparison of staircases with or without rest platforms shows that the flow velocity increases significantly downstream of the rest platform on a straight-run type, which would have negative effects on the safe evacuation of people walking through a flooding staircase. The slope of the staircase, ranging from $26.6^{\circ}$ to $30^{\circ}$, has less effect on safe evacuation. A comparison of flows on straight-run (with or without rest platforms), $90^{\circ}$-turn and $180^{\circ}$-turn staircases (with rest platforms) shows that the rest platforms on the latter two staircases could induce a redistribution of the flow field on the rest platform and downstream. The distribution of evacuation indicators along the longitudinal planes of those staircases indicates that a $90^{\circ}$-turn staircase or a straight staircase without rest platform would be the first choice for trapped people evacuating from underground spaces.
\end{abstract}

Key words: Staircase, Rest platform, Flood, Evacuation, Computational fluid dynamics (CFD) simulation doi: 10.1631 jzus.A1400154

Document code: A

CLC number: TU998

\section{Introduction}

Urban flooding has attracted significant attention recently (Ashley et al., 2005; Taylor et al., 2011; Schubert and Sanders, 2012). When urban flooding occurs, the flooding flow may intrude into underground spaces and threaten people's safety (Inoue et al., 2003; Ishigaki et al., 2005; 2009; Shao, 2010; Kotani et al., 2012; Jiang et al., 2014; Shao et al., 2014). The safe evacuation of trapped people and gaining a better understanding of flooding flow

\footnotetext{
Corresponding author

*Project supported by the Fundamental Research Funds for the Central Universities (No. 2009QNA4024), and the Program for Zhejiang Leading Team of S\&T Innovation (No. 2010R50037), China

(C) ORCID: Wei-yun SHAO, http://orcid.org/0000-0001-8896-8355

(C) Zhejiang University and Springer-Verlag Berlin Heidelberg 2015
}

characteristics on staircases under flooding intrusion have become new challenges for flooding management (Ishigaki et al., 2009; Shao, 2010; Jiang et al., 2014; Shao et al., 2014).

A few experimental studies have been devoted to the safety of people walking through a flooding flow on a staircase without rest platform. Inoue et al. (2003) and Ishigaki et al. (2005) defined an index to indicate the possibility of people walking through a flooding staircase as $F(v, y)=v^{2} y$, where $v$ is the water velocity and $y$ is the depth of water on the staircase. For safe evacuation, Inoue et al. (2003) suggested $1.5 \mathrm{~m}^{3} / \mathrm{s}^{2}$ for $F(v, y)$ by testing people walking on a 1:3-scale staircase model, while Ishigaki et al. (2005) argued that $1.2 \mathrm{~m}^{3} / \mathrm{s}^{2}$ would be safer by testing the stability of people walking on a flooding full-scale staircase model. 
A few other studies have been conducted to evaluate the safe evacuation of people through flooding staircases by numerical simulation. Gotoh et al. (2006) applied a practical method to estimate the hydrodynamic force acting on a model leg installed on a stair. Yoneyama et al. (2009) simulated the flow over a staircase model with the volume of fluid (VOF) method and showed that the computed values for velocity were less than experimental values due to the coarse mesh of each staircase.

Typically, staircases are separated into several segments with no more than 18 steps in each segment, with segments divided by one or more rest platforms to allow people to rest or for staircases to change direction (BUEDRI, 2003; MOHURD, 2005; ICC, 2011). The existence of a rest platform on a staircase can change its hydraulic features and affect the stability of people walking on the flooding staircase. In tests on a 1:2 scale physical model of a straight-run staircase, Shao et al. (2014) found that a free-falling jet occurs downstream of the rest platform, which may affect the walking stability of people on the staircase. Jiang et al. (2014) investigated the jet force on cylinders downstream of the rest platform experimentally and found that the existence of a rest platform in a straight-run staircase can change the hydrodynamic force significantly, which may increase the risk to evacuees just downstream of the rest platform.

The most commonly used forms of staircase in engineering practice in subways are straight-run with or without a rest platform, $90^{\circ}$-turn (L-shaped) and $180^{\circ}$-turn (U-shaped), depending on the surrounding ground and underground environment around the entrance of the subway. The slope of a staircase varies from $26.6^{\circ}$ to $30^{\circ}$. Up to now, the safe evacuation of people on a staircase in underground flooding has not been taken into consideration in engineering design, although the flow properties on different forms of staircase differ significantly. This situation may increase the potential risk to evacuees.

No research has focused on the safe evacuation of people on staircases with different patterns and slopes. To evaluate the effect of the patterns and slopes of staircases on evacuees, in this study numerical models of flooding flows on different kinds of staircases with rest platforms and/or with different slopes were developed and validated by experimental data measured on a physical model of the same-size and based on the data available from previous studies of the flow on staircases and stepped spillways. The effects of different forms of staircase on the flow pattern, air-water velocity and the value of $F\left(v, y_{\mathrm{w}}\right)$ are discussed $\left(y_{\mathrm{w}}\right.$ is the equivalent clear-water flow depth on a step).

The flows on a staircase with no rest platform are similar to those on stepped chutes commonly used for energy dissipation over a wide range of operating heads in steep channels and dams, based on their engineering functions (Felder and Chanson, 2009; Simões et al., 2010; Relvas and Pinheiro, 2011; Takahashi and Ohtsu, 2012). The air-water flow characteristics on stepped chutes for effective energy dissipation or better design guidelines have been studied thoroughly (Chanson, 1994; Felder and Chanson, 2011; Takahashi and Ohtsu, 2012). Results show that the water velocity in a flow on a spillway is almost equal to the air-water velocity when the air concentration $C$ is between 0 and $90 \%$ (Cain, 1978). Therefore, in this study the air-water velocity was used to evaluate $F\left(v, y_{\mathrm{w}}\right)$.

\section{Numerical methodology}

\subsection{Numerical modeling}

Numerical modeling of the flow on a staircase is similar to the simulation of flow on a stepped chute. Chen et al. (2002) used the VOF method in conjunction with a standard $k-\varepsilon$ turbulence model and found that the numerical model is an efficient and useful method to simulate the flow over a stepped spillway. Cheng et al. (2006) used a VOF and mixture model in conjunction with an RNG $k$ - $\varepsilon$ turbulence model to simulate the same case as in (Chen et al., 2002). The results revealed that the RNG $k-\varepsilon$ turbulence model can model the flows on a stepped spillway better than the standard $k-\varepsilon$ turbulence model. Qian et al. (2009) used the VOF method in conjunction with four turbulence models, Realizable $k-\varepsilon$, shear stress transport $k-\omega, v^{2}-f$, and large eddy simulation (LES). They found that the Realizable $k-\varepsilon$ turbulence model 
was the most efficient turbulence model for the simulation of flow over stepped spillways. Tongkratoke et al. (2009) used the LES, the non-linear and the modified non-linear turbulence models to simulate the flow on stepped spillways. The results showed that the Realizable $k-\varepsilon$ model gave the most satisfactory results among the linear turbulence models. Kositgittiwong et al. (2013) used the standard $k-\varepsilon$, Realizable $k-\varepsilon$, Renormalization group $k-\varepsilon$, standard $k-\omega$, and shear stress transport $k-\omega$ models to analyze the velocity profiles on stepped spillways and found that all five turbulence models performed satisfactorily.

Therefore, the VOF model in conjunction with the Realizable $k-\varepsilon$ turbulence model was employed in the present study to simulate flooding flow on a staircase. The commercial software, Fluent 6.3.26, was used to carry out the simulation of intrusive flooding flow over the staircase. The governing equations were discretized using a finite volume method. The coupling of pressure and velocity was achieved through a pressure implicit with splitting of operator (PISO) algorithm. Pressure interpolation was performed using the PRESTO scheme. The momentum equations, volume fraction and turbulent kinetic energy were solved by the QUICK scheme, and the transient formulation was performed using the second order implicit scheme.

\subsection{Computational domain and boundary conditions}

The numerical model domain is based on the 1:2-scale physical model of a straight-run staircase presented by Jiang et al. (2014) and Shao et al. (2014) (Fig. 1). The pseudo-bottom (the connecting line of the step edges) inclination angle is $29.7^{\circ}$, corresponding to a slope of $1: 1.75$. A total of 26 identical steps $(s=0.08 \mathrm{~m}, l=0.14 \mathrm{~m}$, where $s$ is the height and $l$ is the length of each step) and two rest platforms comprise a $0.8 \mathrm{~m}$-wide staircase chute. The first rest platform is located in the middle of the staircase and divides the staircase into two segments, each composed of 13 identical steps. The steps and the rest platforms are numbered sequentially from No. 1 to No. 28 from the top to the bottom of the staircase (Fig. 1).
The origin of the overall Cartesian coordinate system $(X, Y, Z)$ employed in the present study was located at the inlet of the step chute (Fig. 1), with the $X$ axis in the horizontal direction, the $Z$ axis in the vertical direction, and the $Y$ axis perpendicular to those two directions (cross-stream direction). The upstream boundary of the model was set at $0.5 \mathrm{~m}$ upstream from the inlet of the elevated step in the $X$-direction. The downstream boundary was at the outlet of the step chute. At the inlet boundary (lower part of the inlet), a uniform flow was imposed with the flow velocity obtained from the physical model. A pressure-inlet boundary with atmospheric pressure was set at the upper part of the inlet and the upper opening of the model. A pressure-outlet boundary with atmospheric pressure was adopted at the outlet. A no-slip wall boundary condition was applied at the lateral wall of the staircase, the step faces, and the rest platform faces.

For the convenience of discussion, a local coordinate system was defined on each step edge. Its origin is located at the step edge, the $x$-direction is along the pseudo-bottom of the staircase and the $y$-direction for the water depth is perpendicular to the $x$-direction and the transverse of the staircase.

A structured grid was used to mesh the cells (Fig. 1b), and standard wall functions were employed for the near-wall cells (Launder and Spalding, 1974). The near-wall turbulent quantities were controlled by the wall $Y$ plus $\left(y^{+}\right)$, the values of which in the present study were between 30 and 300 (Ariff et al., 2009; Salim and Cheah, 2009), by refining the mesh automatically near the wall, based on geometric and numerical solution data during the solution process.

\subsection{Mesh independence}

Four mesh sizes were tested for assessing the effect of grid sensitivity on the accuracy of the numerical model and to determine the mesh density for the problem to be simulated (Table 1). Fig. 2 compares the simulated air-water mixture depth over step edges for different mesh sizes along the centerline of the step chute, in which $y_{90}$ is the air-water mixture depth at the step edge and $y_{\mathrm{c}}$ is the critical depth. The air-water mixture depths over step edges do not change very much for the cases of Mesh 2, 


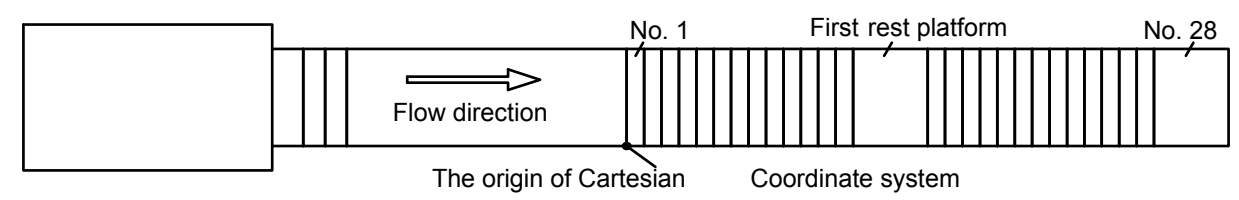

(a)

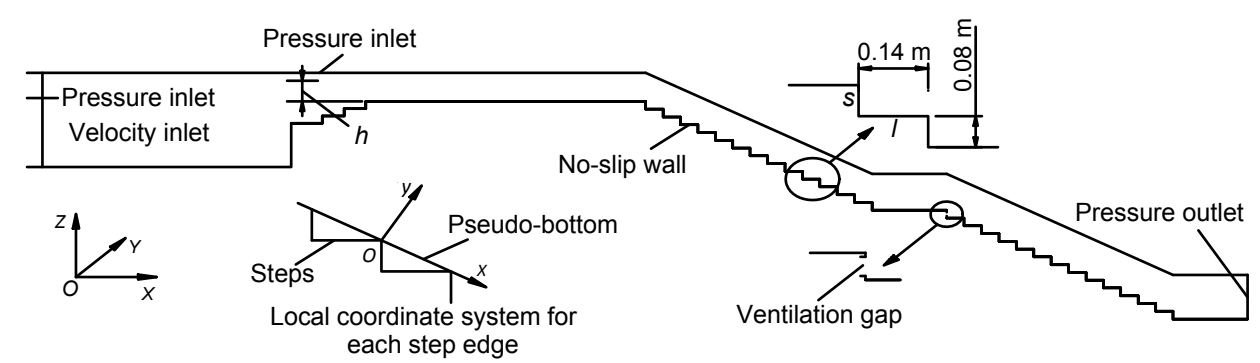

(b)
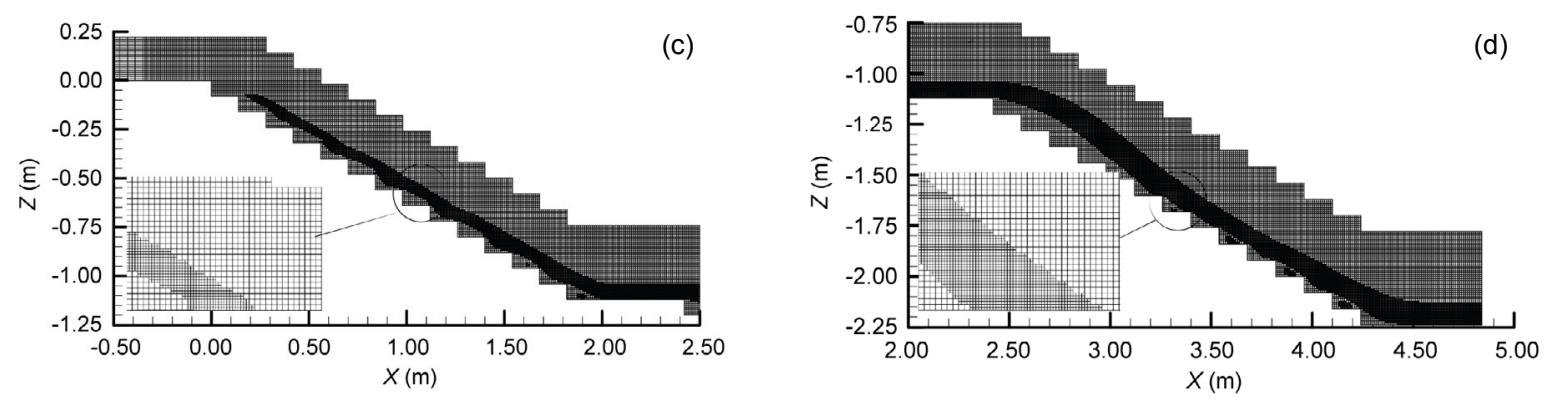

Fig. 1 Computational domain and boundary conditions of staircase at top view (a) and side view (b), and mesh discretion of upper segment (c) and lower segment (d)

Table 1 Mesh schemes of the simulation model

\begin{tabular}{cccc}
\hline Mesh & Node & Element & $\begin{array}{c}\text { Max. mesh size on the } \\
\text { step chute }(\mathrm{mm})\end{array}$ \\
\hline 1 & 369207 & 401964 & 15 \\
2 & 795906 & 743526 & 12 \\
3 & 1234040 & 1306936 & 10 \\
4 & 2575335 & 2460575 & 8 \\
\hline
\end{tabular}

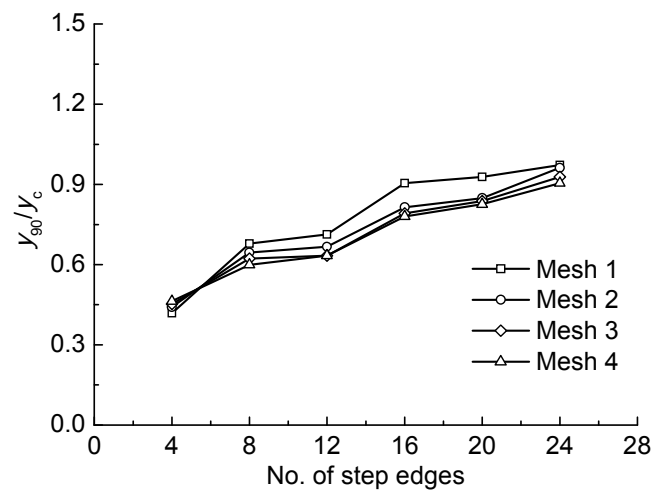

Fig. 2 Mesh refinement in the numerical model of airwater mixture depth over step edges
Mesh 3 and Mesh 4, as the mesh refines. Accordingly, Mesh 3 was used in the present study, which had 1306936 elements constructed by 1234040 nodes with a maximum mesh size of $10 \mathrm{~mm}$ on the step chute.

\subsection{Case study}

Generally, staircases for people walking include straight-run staircases with rest platforms, L-shaped staircases with $90^{\circ}$-turns and U-shaped staircases with $180^{\circ}$-turns (Fig. 3, where $B$ is the width of staircase and $b$ is the distance from side wall of step), and escalators with no rest platform (BUEDRI, 2003; MOHURD, 2005; ICC, 2011). The slope of a staircase ranges from about $26.6^{\circ}$ to $30^{\circ}$ (BUEDRI, 2003; MOHURD, 2005). Therefore, six models (Table 2) were chosen as the study scenarios, and three comparisons were made: $\mathrm{C} 1$ and $\mathrm{C} 2$, for evaluation of the effect of the rest platform; $\mathrm{C} 1, \mathrm{C} 3$, and $\mathrm{C} 4$, for evaluation of the effect of the staircase slope, in which $\mathrm{C} 1$ 
has a slope of $29.7^{\circ}$ with a step height $s=0.08 \mathrm{~m}$ and a step length $l=0.14 \mathrm{~m}, \mathrm{C} 3$ has a slope of $28.1^{\circ}$ with $l=0.15 \mathrm{~m}$, and $\mathrm{C} 4$ has a slope of $26.6^{\circ}$ with $l=0.16 \mathrm{~m}$; $\mathrm{C} 1, \mathrm{C} 5$ and $\mathrm{C} 6$, for evaluation of the effect of different staircase patterns: straight-run with a rest platform (C1), L-shaped (C5), and U-shaped (C6). Ishigaki et al. (2005) concluded that it would be very difficult for people to evacuate safely from underground space through a flooding staircase if the ground water depth $h$ ( $h$ is the depth of incoming water at the entrance of the staircase, as shown in Fig. 1a) is over $30 \mathrm{~cm}$, that is, $15 \mathrm{~cm}$ in the $1: 2$-scale model used in the present study. Therefore, a ground water depth of $15 \mathrm{~cm}$ was chosen for our model study.

Table 2 Summary of the simulation scenarios in the present study

\begin{tabular}{cccc}
\hline Ref. & $\begin{array}{c}\text { Slope of pseudo- } \\
\text { bottom of staircase }\end{array}$ & $\begin{array}{c}\text { Existence of } \\
\text { rest platform }\end{array}$ & $\begin{array}{c}\text { Type of the } \\
\text { staircase }\end{array}$ \\
\hline C1 & $29.7^{\circ}$ & Yes & Straight-run \\
C2 & $29.7^{\circ}$ & No & Straight-run \\
C3 & $28.1^{\circ}$ & Yes & Straight-run \\
C4 & $26.6^{\circ}$ & Yes & Straight-run \\
C5 & $29.7^{\circ}$ & Yes & $\begin{array}{c}\text { L-shaped } \\
\left(90^{\circ} \text {-turn }\right)\end{array}$ \\
C6 & $29.7^{\circ}$ & Yes & $\begin{array}{l}\text { U-shaped } \\
\left(180^{\circ} \text {-turn }\right)\end{array}$ \\
\hline
\end{tabular}

\subsection{Validation of the numerical model}

A jet flow occurred downstream of the first rest platform of the straight-run staircase in the experiments, and an air cavity formed under the jet due to the drop in elevation of the steps (Shao et al., 2014). However, the flow downstream of the rest platform in the numerical simulation adhered to the step vertical face, and no jet formed (Fig. 4a) if no air was supplied under the jet. Therefore, to ensure the formation of the jet downstream of the first rest platform, a ventilation gap was opened at the vertical face of the No. 15 step, the first step downstream of the first rest platform (Fig. 1a), and a pressure-inlet boundary with atmospheric pressure was applied. Fig. 4b shows the numerically simulated flow pattern along the step chute with the ventilation gap opened and $h=15 \mathrm{~cm}$. The jet and the air cavity under the jet tongue can be clearly seen to be similar to those described by Shao et al. (2014). The location of the jet re-attachment in both the numerical simulation and the experiment is at step No. 20. The cavity pressures under the jet tongue are near atmospheric pressure.

Fig. 5 shows the computed air-water interface on the steps and the outline of the jet compared to the corresponding measured data presented by Shao et al. (2014). The numerical results agree well with the measured data.

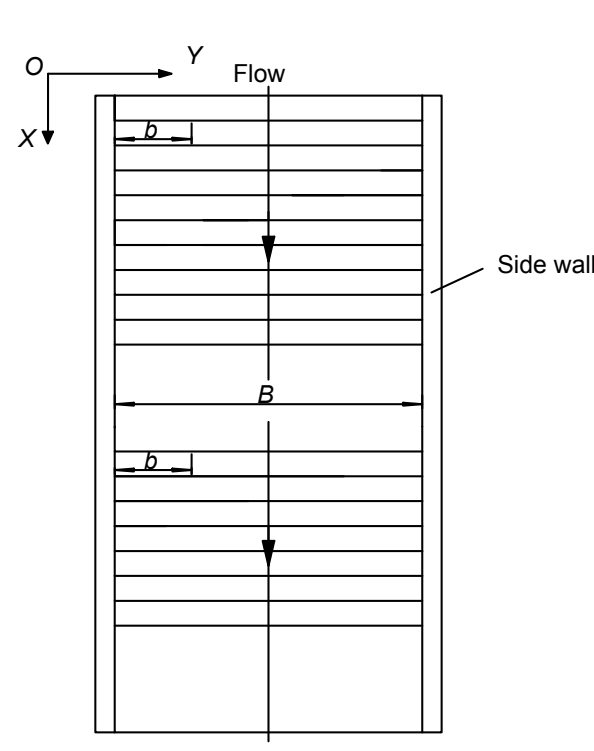

(a)

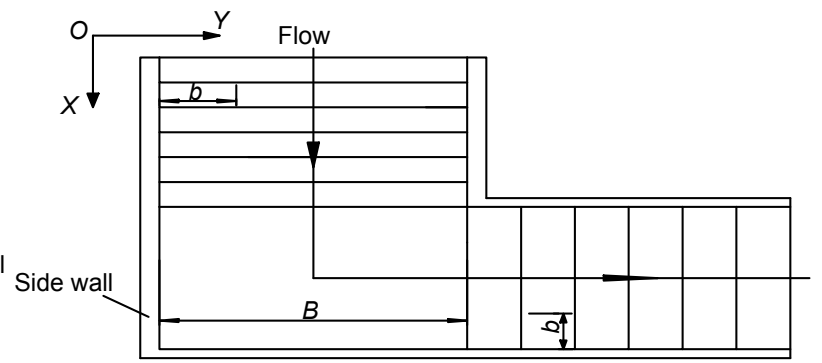

(b)

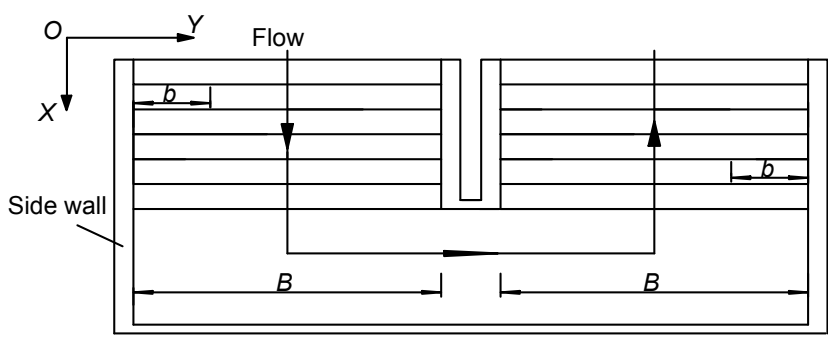

(c)

Fig. 3 Schematics of three different types of the staircases (a) C1: straight-run; (b) C5: L-shaped; (c) C6: U-shaped 

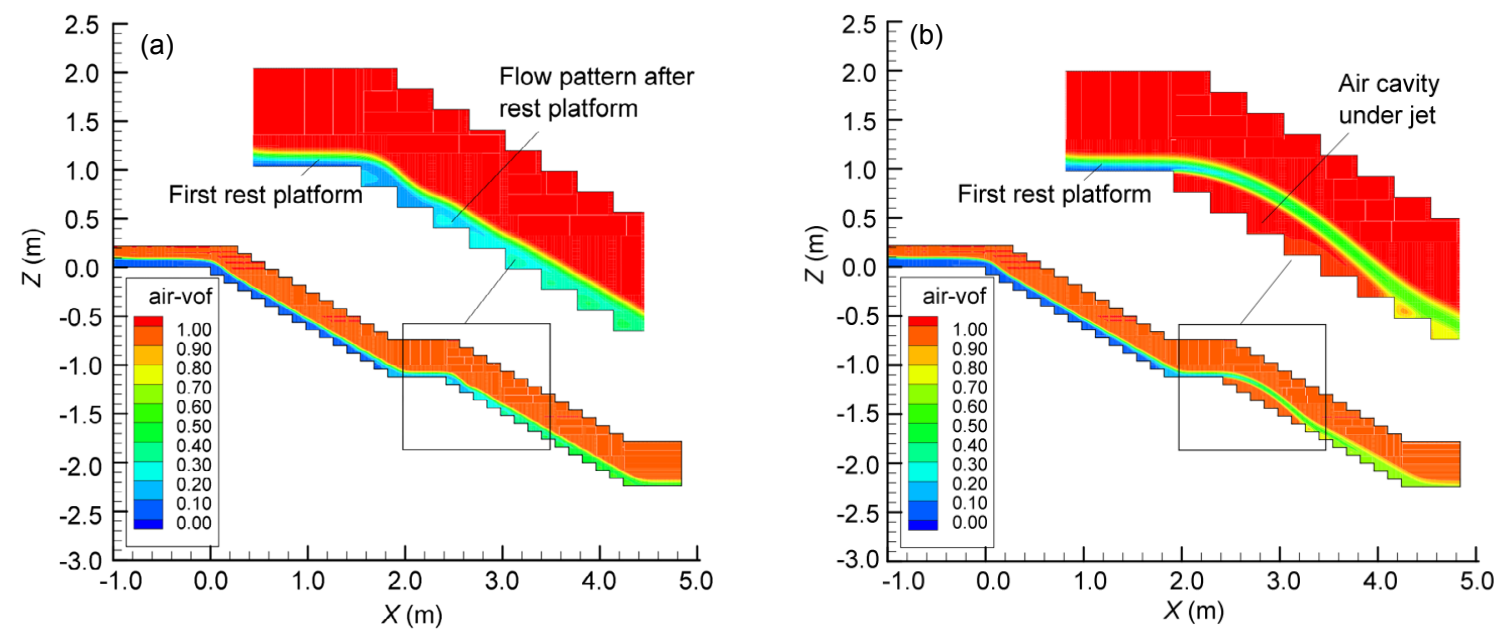

Fig. 4 Simulated flow pattern along the staircase without ventilation (a) and with ventilation (b)

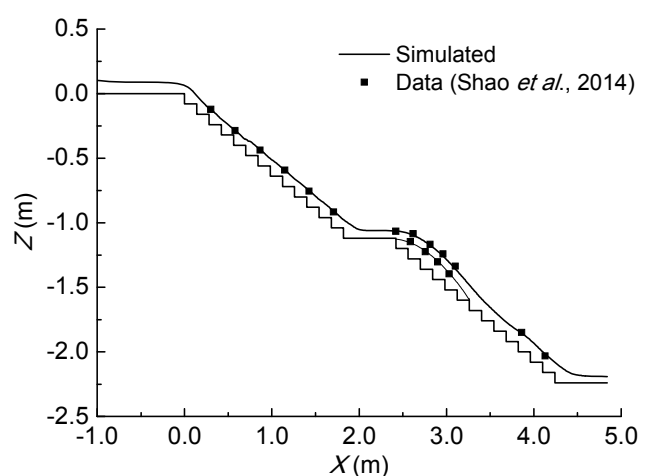

Fig. 5 Air-water interface obtained by simulation and measurement

Figs. $6 \mathrm{a}$ and $6 \mathrm{~b}$ show the air-water mixture velocity vectors and streamlines, colored by the air concentration, in the symmetric longitudinal planes of steps No. 12 and No. 24, in which $\Delta s$ and $\Delta l$ are the vertical and horizontal distances starting from the intersection line of each step's horizontal and vertical faces, respectively. A circulation eddy over each step can be observed under the pseudo-bottom, and its center locates about $3 \mathrm{~cm}$ above the step horizontal face. Figs. $6 \mathrm{c}$ and $6 \mathrm{~d}$ show the velocity distributions in the transverse sections of steps No. 12 and No. 24 with different $\Delta l$ when $h=15 \mathrm{~cm}$. When the transverse section is close to the step vertical face, such as when $\Delta l=3.0 \mathrm{~cm}$ to $9.0 \mathrm{~cm}$, the velocity increases from zero on the step horizontal face to a certain distance away from the step horizontal face. It then decreases and then increases due to the effect of the existing eddy under the pseudo-bottom. Finally, the velocity increases quickly once it is over the pseudo-bottom, reaching its maximum near the interface. These results are consistent with the distributions of the velocity vector and the transverse velocity of skimming flow on a stepped spillway presented by Chen $e t$ al. (2002), Boes and Hager (2003), and Cheng et al. (2006).

In skimming flow, the distribution of air concentration, $C$, at the step edges closely follows the analytical model of air bubble diffusion (Chanson and Toombes, 2001; 2003):

$$
C=1-\tanh ^{2}\left(K^{\prime}-\frac{\frac{y}{y_{90}}}{2 D_{0}}+\frac{\left(\frac{y}{y_{90}}-\frac{1}{3}\right)^{3}}{3 D_{0}}\right)
$$

where $y$ is the water depth above the pseudo-bottom of a stepped chute defined in a local coordinate system (Fig. 1a); $K^{\prime}$ is an integration constant and $D_{0}$ is a function of the mean air concentration only; and $y_{90}$ is the depth of the air-water interface above the pseudobottom of the staircase where the air concentration $C=90 \%$.

Comparisons of the computed air concentration distributions at the edges of steps No. 8 and No. 12 with the measured data from Shao et al. (2014) are presented in Fig. 7. The results of the simulation model compare favorably with the measured data and with Eq. (1) for the skimming flows. 


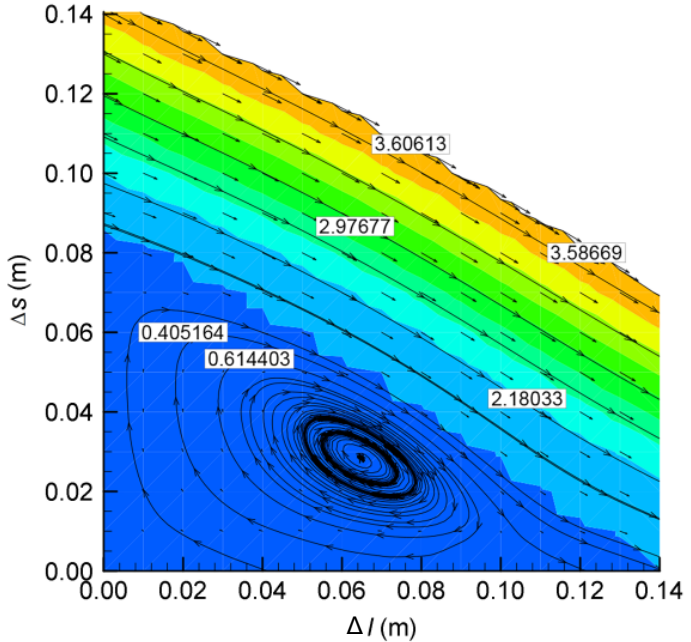

(a)

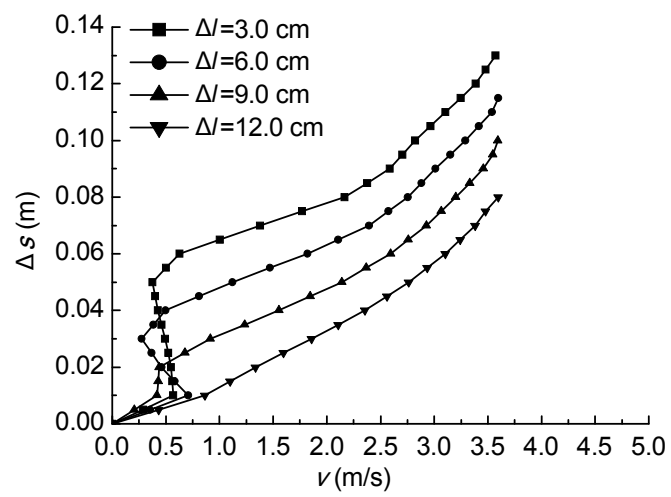

(c)

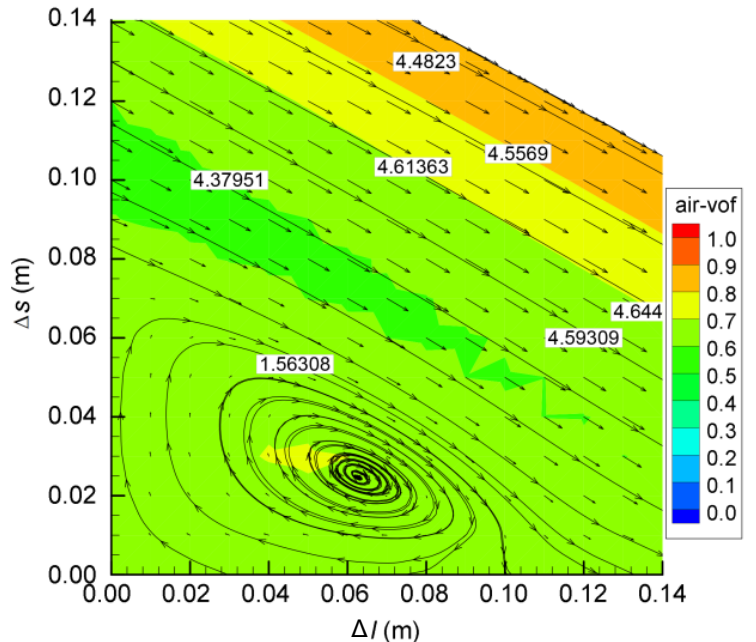

(b)

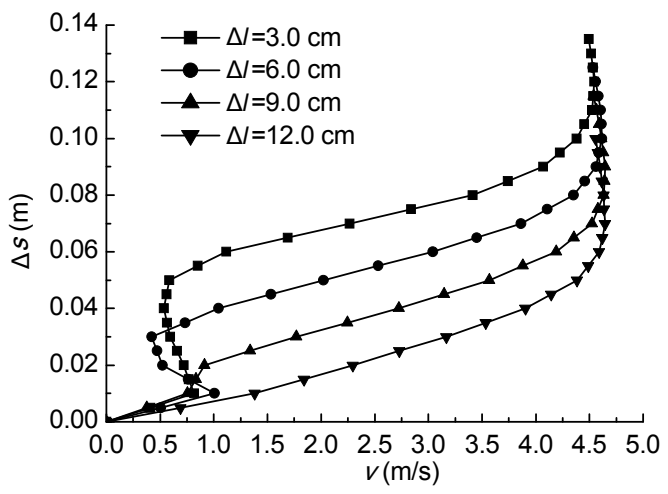

(d)

Fig. 6 Velocity vector and streamlines in the symmetric longitudinal plane of step No. 12 (a) and step No. 24 (b), and velocity distribution at the transverse cross sections over step No. 12 (c) and step No. 24 (d). The data in (a) and (b) are the values of mixture velocities at a point $(\mathrm{m} / \mathrm{s})$

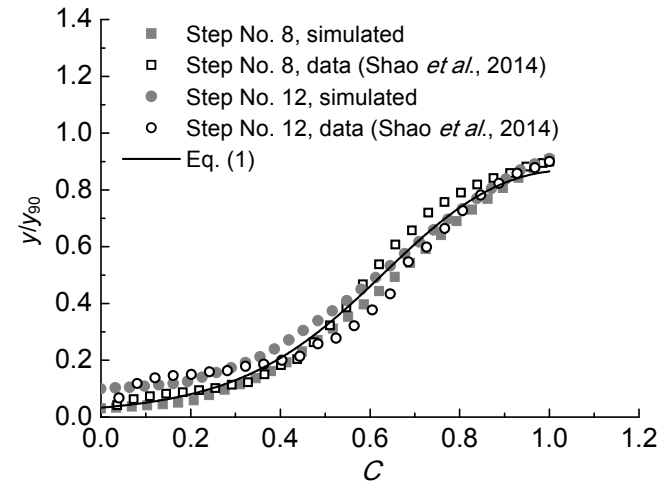

Fig. 7 Comparison of air-concentration distributions at the edges of steps No. 8 and No. 12

In summary, the VOF model in conjunction with the Realizable $k-\varepsilon$ turbulence model can successfully simulate the flow on a staircase and the jet downstream of the first rest platform. Thus, the numerical model employed above is suitable for simulating the flow on a staircase with rest platforms.

\section{Results and discussion}

\subsection{Effect of a rest platform in a straight-run staircase}

The mean air-water mixture velocity on the stepped chute $v_{\mathrm{m}}$ was defined by Ohtsu et al. (2004) as

$$
v_{\mathrm{m}}=\frac{1}{d_{90}} \int_{y_{\mathrm{a}}}^{y_{\mathrm{b}}} v \mathrm{~d} y,
$$


where $v_{\mathrm{m}}$ is the depth-averaged air-water mixture velocity; $v$ is the air-water mixture velocity; $y_{\mathrm{a}}$ and $y_{\mathrm{b}}$ are the characteristic depths of flow, for the transition flow or the skimming flow, $y_{\mathrm{a}}=0$ and $y_{\mathrm{b}}=y_{90}$; for the free-falling jet downstream of the first rest platform, $y_{\mathrm{a}}=y_{90}^{\mathrm{L}}$ and $y_{\mathrm{b}}=y_{90}^{\mathrm{U}}$, where $y_{90}^{\mathrm{U}}$ and $y_{90}^{\mathrm{L}}$ are the characteristic depths defined at the upper and lower air-water interfaces of the jet where $C=90 \%$, as defined by Shao et al. (2014); and $d_{90}$ is the distance from $y_{\mathrm{a}}$ to $y_{\mathrm{b}}$.

Fig. 8a shows the mean air-water mixture velocity $v_{\mathrm{m}}$ and the air-water interface velocity $v_{\mathrm{f}}$ along the symmetric longitudinal plane of flow above the pseudo-bottom. For the case of the staircase with no rest platform $(\mathrm{C} 2)$, once the flooding water intrudes into the staircase, both the mean air-water mixture velocity $v_{\mathrm{m}}$ and the interface velocity $v_{\mathrm{f}}$ begin to increase due to gravity until they reach a nearly constant value; that is, the velocity almost maintains a constant value along the staircase, just as in a skimming flow (Gonzalez et al., 2008; Felder and Chanson, 2009).

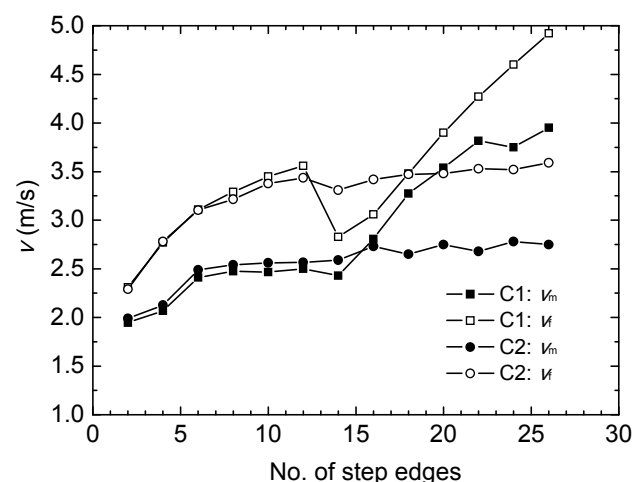

(a)

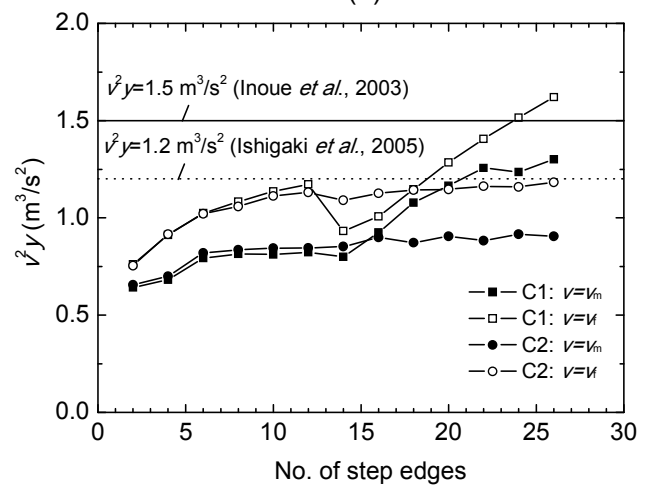

(b)

Fig. 8 Effect of the rest platform on the air-water mixture velocity (a) and the value of $F\left(v, y_{w}\right)$ (b) along the symmetric longitudinal plane above the pseudo-bottom
For the case of the straight-run staircase with a rest platform $(\mathrm{C} 1)$, the mean air-water mixture velocity $v_{\mathrm{m}}$ and the interface velocity $v_{\mathrm{f}}$ also reach a nearly constant value before the rest platform (step No. 14), then the velocities decrease suddenly on the brink of step No. 14 (the rest platform). The trend in the simulated interface velocity $v_{\mathrm{f}}$ over steps No. 1 to No. 13 in this study is consistent with the trend in interface velocity measured in experiments on a realscale staircase by Ishigaki et al. (2005), if the rest platform is considered as the underground space presented in their experiments. Downstream of the first rest platform, a jet occurs. Both the mean and interface velocities increase quickly in the jet drop and keep increasing after the jet plunges into the flow on the downstream steps of the second stair segment, which is very different from the expected velocity on a staircase with no rest platform.

Fig. $8 \mathrm{~b}$ shows that the trends of $F\left(v, y_{\mathrm{w}}\right)$ based on the mean air-water mixture velocity $v_{\mathrm{m}}$ and the air-water interface velocity $v_{\mathrm{f}}$ at the step edges are similar to those of the velocity distribution along the staircase, in which the values of $F\left(v, y_{\mathrm{w}}\right)$ have been converted into the value in prototype scale for comparison with the values of the indicator $F\left(v, y_{\mathrm{w}}\right)$ proposed by Ishigaki et al. (2005) and Inoue et al. (2003), namely $1.2 \mathrm{~m}^{3} / \mathrm{s}^{2}$ and $1.5 \mathrm{~m}^{3} / \mathrm{s}^{2}$, respectively. Because of the effect of the rest platform, the magnitude of $F(v$, $\left.y_{\mathrm{w}}\right)$ also decreases near step No. 14, which could slightly reduce the risk for people evacuating through the flooding staircase. However, the magnitude of $F(v$, $y_{\mathrm{w}}$ ) on the staircase with a rest platform recovers from the decrease and achieves a larger value in the jet due to a larger velocity occurring downstream of the jet (Fig. 8a), while $F\left(v, y_{\mathrm{w}}\right)$ on the staircase without a rest platform remains nearly constant along the staircase. Therefore, the existence of a rest platform for a straight-run staircase will make it more difficult for trapped people to evacuate safely from an underground space through inundated staircases downstream of the rest platform.

\subsection{Effect of the staircase slope in a straight-run staircase}

Fig. 9 shows the effect of the staircase slope on the mean air-water mixture velocity and the value of 
$F\left(v, y_{\mathrm{w}}\right)$ along the symmetric longitudinal plane above the pseudo-bottom. Both the air-water mixture velocity and the value of $F\left(v, y_{\mathrm{w}}\right)$ along the staircase do not change very much with the change in staircase slope from $26.6^{\circ}$ to $29.7^{\circ}$. This is because the slope of staircases varies very little according to the design guides of BUEDRI (2003) and MOHURD (2005), and for all three cases the jet occurs downstream of the rest platform with a similar trajectory length. Therefore, the slope of a staircase has little effect upon the stability of people walking on a flooding staircase.

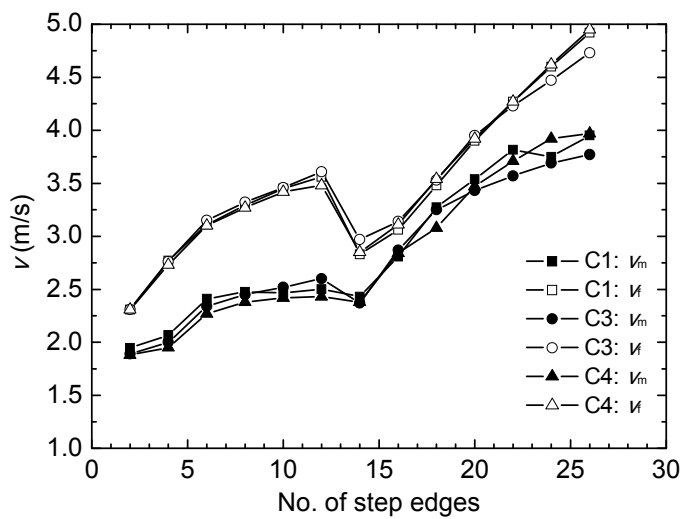

(a)

\subsection{Effect of staircase patterns}

Figs. 10 and 11 show the flow patterns on the planes along the upper and lower segments of the L-shaped (C5) and U-shaped (C6) staircases with different $b$. The flow pattern on the straight-run staircase (C1) is shown in Fig. 4b. Similar flow patterns can be seen on the upper segment upstream of the first rest platform for all three staircase types. For the flow on the rest platform and the lower segment of the staircases, however, the L-shaped and U-shaped staircases have a very different flow

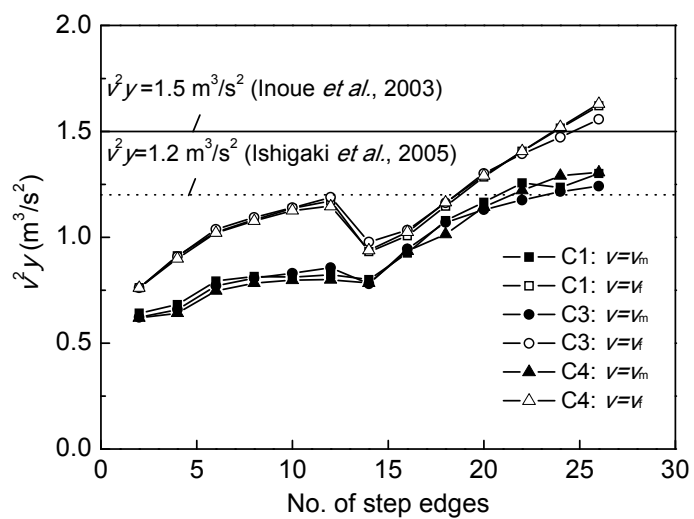

(b)

Fig. 9 Effect of staircase slope on the air-water mixture velocity (a) and the value of $F(v, y)(b)$ along the symmetric longitudinal plane above the pseudo-bottom
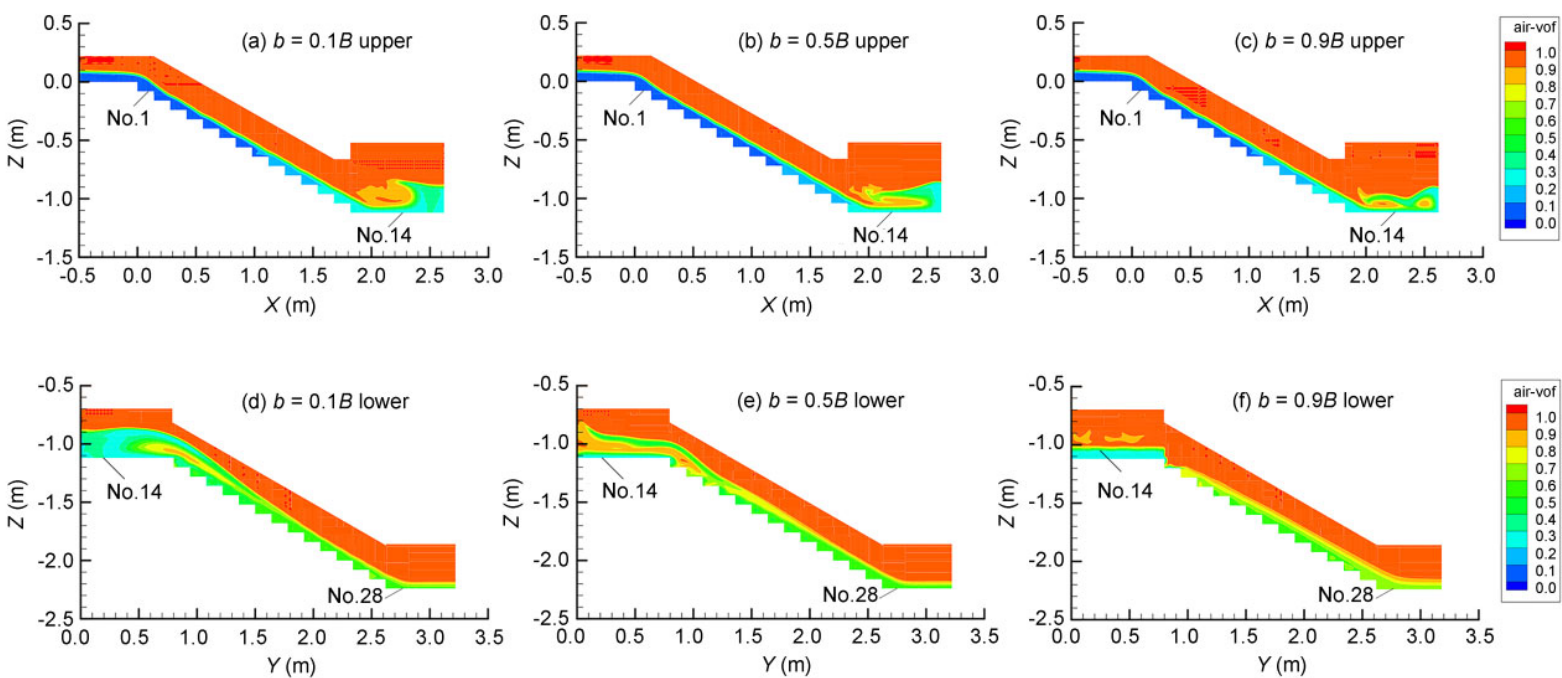

Fig. 10 Flow pattern colored by the air concentration on the upper segment (a)-(c) and lower segment (d)-(f) of L-shaped staircase (C5) with different $b$ 
pattern compared to the straight-run staircase. The jet occurring downstream of the first rest platform of the straight-run staircase (Fig. 4b) cannot be clearly delineated on the U-shaped staircase, while a much larger profile of the jet with a small $b$ downstream of the rest platform can be seen on the L-shaped staircase in Fig. 10d.

Fig. 12 shows the velocity vectors and streamlines in the horizontal planes $0.05 \mathrm{~m}$ above the horizontal surfaces of the rest platforms of straight-run (C1), L-shaped (C5), and U-shaped (C6) staircases.
For the straight-run staircase, the flow past the rest platform moves smoothly and the velocity distribution on the rest platform is nearly uniform because there is no disturbance in the flow direction. However, the flow changes its direction by $90^{\circ}$ for the L-shaped staircase and by $180^{\circ}$ for the U-shaped staircase with the effect of the side wall. The flow distributions on the rest platforms of the L-shaped and U-shaped staircases are seriously disturbed by the side wall and are re-developed. Once water reaches the side wall of the rest platform, the flow reflects back with a large
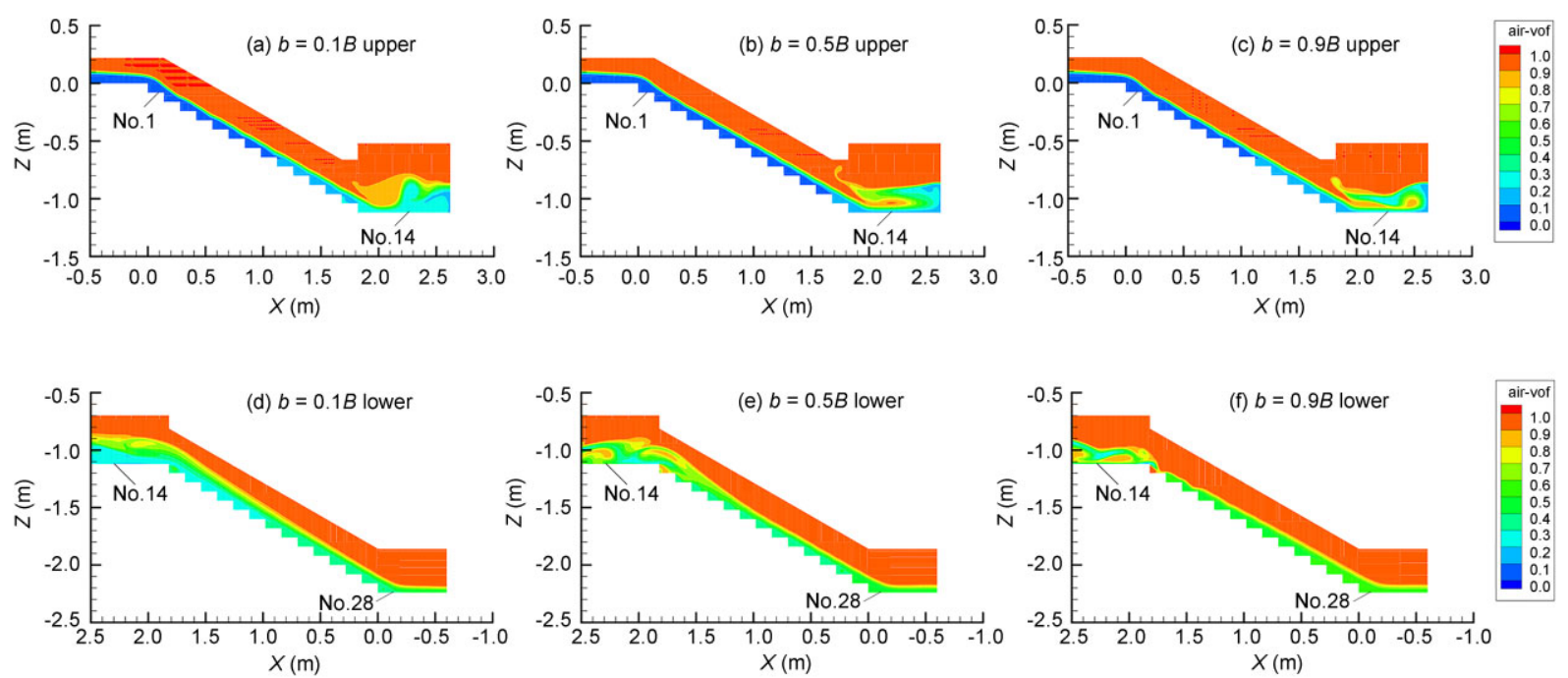

Fig. 11 Flow pattern colored by the air concentration on the upper segment (a)-(c) and lower segment (d)-(f) of a U-shaped staircase (C6) with different $b$

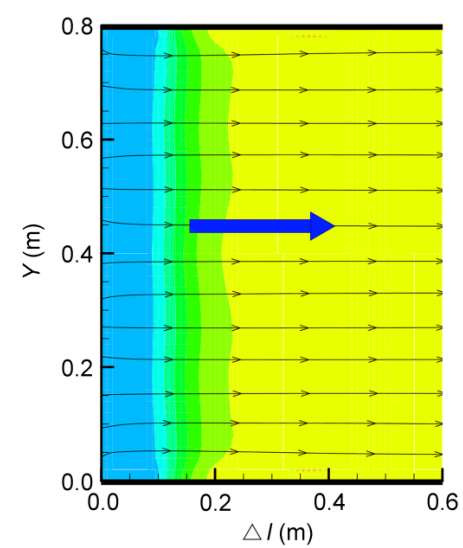

(a)

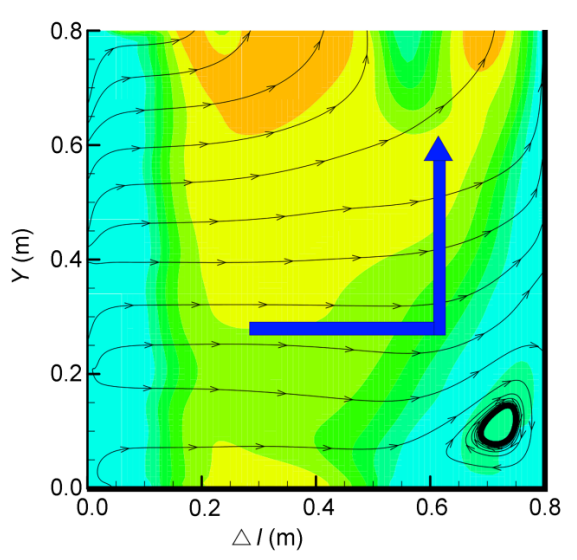

(b)

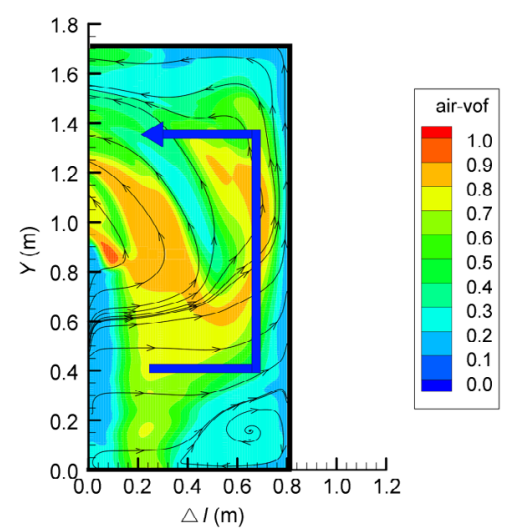

(c)

Fig. 12 Velocity vector and streamlines colored by the air concentration in the horizontal plane $0.05 \mathrm{~m}$ above the bottom of rest platform for different cases. The bold line and arrow indicate the direction of the water flow

(a) C1: straight-run; (b) C5: L-shaped; (c) C6: U-shaped 
rotating zone and the air-water mixture depth increases (Figs. 10 and 11).

Fig. 13 shows the mean air-water velocities and the values of $F\left(v_{\mathrm{m}}, y_{\mathrm{w}}\right)$ along the staircases above the pseudo-bottoms under different distances of $b$. The mean air-water mixture velocity and the value of $F\left(v_{\mathrm{m}}\right.$, $y_{\mathrm{w}}$ ) upstream of the rest platform with different $b$ are almost unchanged for all kinds of staircases, which means the rest platform has little effect on the flow upstream. For the flow on the lower stair segment of the straight-run staircase, the distance $b$ also has little effect upon the velocity and the value of $F\left(v_{\mathrm{m}}, y_{\mathrm{w}}\right)$. For the L-shaped staircase, a smaller but increasing mean air-water mixture velocity occurs along the plane with increasing distance of $b(=0.9 B)$ on the lower stair segment, which results in an increase in $F\left(v_{\mathrm{m}}, y_{\mathrm{w}}\right)$ from steps No. 16 to No. 26 . For the plane with a small distance $b(=0.1 B)$, a sudden increase in $F\left(v_{\mathrm{m}}, y_{\mathrm{w}}\right)$ occurs from steps No. 14 to No. 16 and then decreases until step No. 26. However, $F\left(v_{\mathrm{m}}, y_{\mathrm{w}}\right)$ in all of those zones does not exceed $1.2 \mathrm{~m}^{3} / \mathrm{s}^{2}$ and thus is safe for people walking. For the U-shaped staircase, the flow velocities keep increasing from steps No. 14 to No. 26. However, the distance $b$ has a larger effect on the flow velocity and the value of $F\left(v_{\mathrm{m}}, y_{\mathrm{w}}\right)$ on the lower segment compared to the case of the L-shaped staircase. A smaller distance $b$ has a larger velocity and larger value of $F\left(v_{\mathrm{m}}, y_{\mathrm{w}}\right)$ due to its larger velocity (Fig. 13c) and larger flow depth (Fig. 11d). The values of $F\left(v_{\mathrm{m}}, y_{\mathrm{w}}\right)$ in the zone with small distance $b(=0.1 B)$ exceed $1.2 \mathrm{~m}^{3} / \mathrm{s}^{2}$ from steps No. 16 to No. 26 , which would make it very difficult for people to evacuate through the staircase. However, if $F\left(v_{\mathrm{f}}, y_{\mathrm{w}}\right)$ is taken as the criterion determining the safety of evacuation, the risk could be larger because $v_{\mathrm{f}}$ is always greater than $v_{\mathrm{m}}$ (Fig. 9).

As discussed above, the form of a staircase in a subway entrance depends mainly on the ground and underground environments surrounding the entrance. The results of this study show that an L-shaped form would be the first choice for evacuation of people once underground flooding occurs. Therefore, if it is possible in the engineering design, the L-shaped staircase should be a priority choice for subway entrances.

\section{Conclusions}

A CFD numerical model of a staircase with rest platforms has been developed in this study to simulate the flooding intrusion flow on a staircase, while a
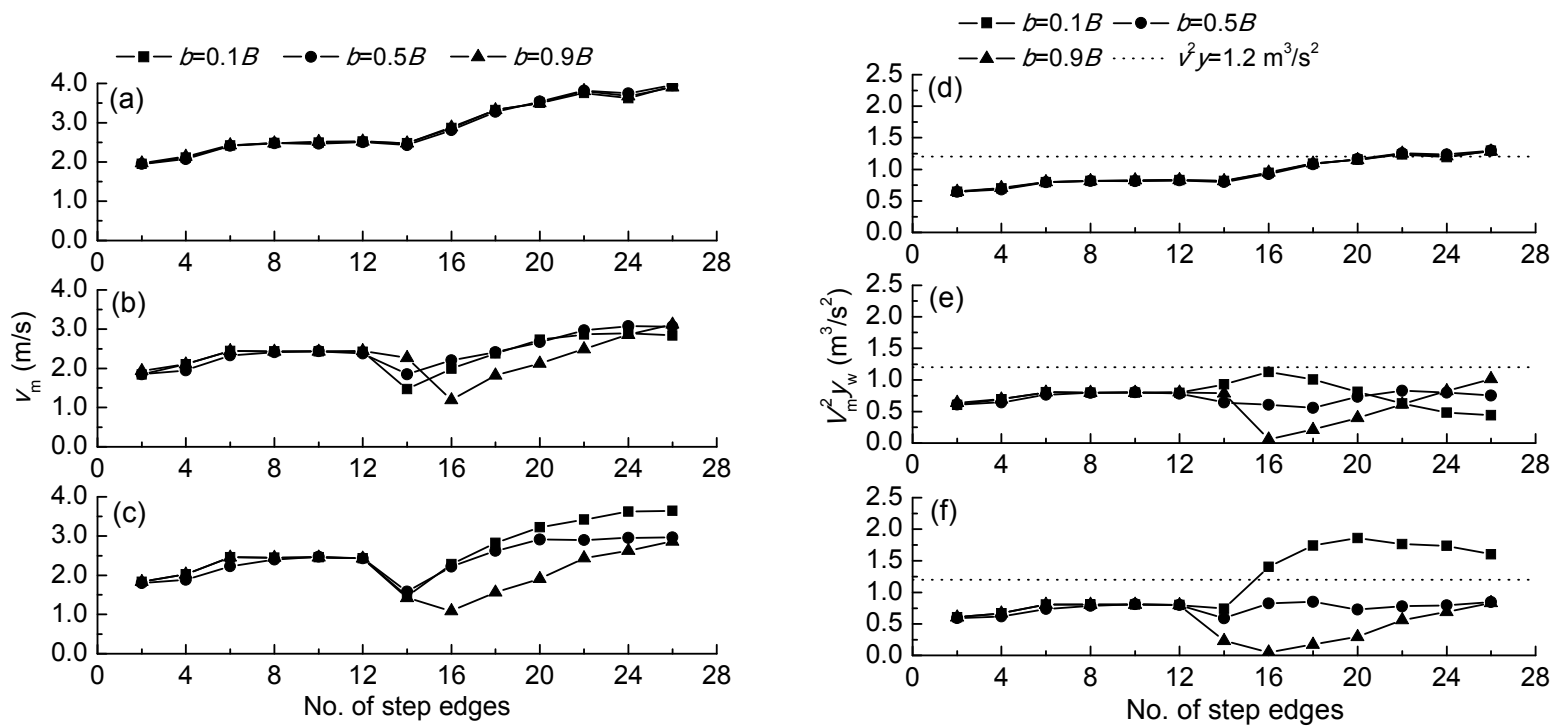

Fig. 13 Values of the mean air-water mixture velocity (a)-(c) and $F\left(v, y_{w}\right)$ (d)-(f) along the stepped chutes of three types of staircases

(a) and (d) C1: straight-run; (b) and (e) C5: L-shaped; (c) and (f) C6: U-shaped 
ventilation gap was introduced to the model to ensure the formation of an air cavity and a jet downstream of the rest platform. The numerical model was validated using data measured on a same size physical model of a staircase and by comparison to published experimental and numerical data on staircases and stepped spillways. The validation of the CFD model shows the numerical model employed in this study is feasible for the simulation of the flow on a staircase with rest platforms.

The effect of the rest platform, the staircase slope and the staircase pattern on the flow pattern, the mean air-water mixture velocity, and the value of the evacuation risk indicator $F\left(v, y_{\mathrm{w}}\right)$ were investigated and discussed. The existence of rest platforms between staircase segments can greatly change the flow characteristics on the rest platform and the steps downstream. Unlike the nearly constant velocity of the upper segment of a straight-run staircase, the velocity downstream of the rest platform increases significantly along the direction of flow, which may affect the safe evacuation of people through the inundated staircase. So it would be safer for people to use a staircase without rest platforms to avoid the dramatic rise in the magnitude of $F\left(v, y_{\mathrm{w}}\right)$ downstream of a rest platform. The slope of a straight-run staircase has little effect on evacuation due to the small range in the slope of staircases (from $26.6^{\circ}$ to $30^{\circ}$ ). Therefore, people can choose to use an escalator through a flooding flow if the power has been cut off, even if it has a relatively steep slope. Both L-shaped and U-shaped staircases can redistribute the flow field on the rest platform, while an L-shaped staircase can lessen the risk of trapping people on the lower stair segment downstream of the rest platform compared to a straight-run staircase. Therefore, the L-shaped type would be the first choice for people evacuation. People going upstairs should walk in the middle or on the left of the lower segment of an L-shaped staircase, and in the middle or on the right of the lower segment of a U-shaped staircase.

In summary, when flooding occurs on a staircase, trapped people should choose an L-shaped staircase or a staircase without rest platforms for ease of evacuation.

\section{References}

Ariff, M., Salim, S.M., Cheah, S.C., 2009. All $Y^{+}$approach for dealing with turbulent flow over a surface mounted cube: part II-high Reynolds number. 7th International Conference on CFD in the Mineral and Process Industries, Australia.

Ashley, R.M., Balmforth, D.J., Saul, A.J., et al., 2005. Flooding in the future-predicting climate change, risks and responses in urban areas. Water Science and Technology, 52:265-273.

Boes, R.M., Hager, W.H., 2003. Two-phase flow characteristics of stepped spillways. Journal of Hydraulic Engineering, 129(9):661-670. [doi:10.1061/(ASCE)07339429(2003)129:9(661)]

BUEDRI (Beijing Urban Engineering Design \& Research Institute Co., Ltd.), 2003. Code for Design of Metro. China Planning Press (in Chinese).

Cain, P., 1978. Measurements within self-aerated flow on a large spill-way. Research Report, Department of Civil Engineering, University of Canterbury, New Zealand, p. 650 .

Chanson, H., 1994. Hydraulics of skimming flows over stepped channels and spillways. Journal of Hydraulic Research, 32(3):445-460. [doi:10.1080/002216894094 98745]

Chanson, H., Toombes, L., 2001. Experimental investigations of air entrainment in transition and skimming flows down a stepped chute: application to embankment overflow stepped spillways. Department of Civil Engineering, University of Queensland.

Chanson, H., Toombes, L., 2003. Strong interactions between free-surface aeration and turbulence in an open channel flow. Experimental Thermal and Fluid Science, 27(5): 525-535. [doi:10.1016/S0894-1777(02)00266-2]

Chen, Q., Dai, G., Liu, H., 2002. Volume of fluid model for turbulence numerical simulation of stepped spillway overflow. Journal of Hydraulic Engineering, 128(7): 683-688. [doi:10.1061/(ASCE)0733-9429(2002)128:7 (683)]

Cheng, X., Chen, Y., Luo, L., 2006. Numerical simulation of air-water two-phase flow over stepped spillways. Science in China Series E: Technological Sciences, 49(6): 674-684. [doi:10.1007/s10288-006-2029-2]

Felder, S., Chanson, H., 2009. Energy dissipation, flow resistance and gas-liquid interfacial area in skimming flows on moderate-slope stepped spillways. Environmental Fluid Mechanics, 9(4):427-441. [doi:10.1007/s10652009-9130-y]

Felder, S., Chanson, H., 2011. Air-water flow properties in step cavity down a stepped chute. International Journal of Multiphase Flow, 37(7):732-745. [doi:10.1016/j. ijmultiphaseflow.2011.02.009]

Gonzalez, C.A., Takahashi, M., Chanson, H., 2008. An 
experimental study of effects of step roughness in skimming flows on stepped chutes. Journal of Hydraulic Research, 46(S1):24-35. [doi:10.1080/00221686.2008. 9521937]

Gotoh, H., Ikari, H., Sakai, T., et al., 2006. Computational mechanics of a force on a human leg in flow over a underground staircase in urban flood. Annual Journal of Hydraulic Engineering, JSCE, 60:865-870 (in Japanese).

ICC (International Code Council), 2011. International Building Code (IBC). ICC (Distributed by Cengage Learning), 500 New Jersey Avenue, NW, Washington, DC 20001.

Inoue, K., Toda, K., Nakai, T., et al., 2003. On the inundation process in the underground space. Annuals of Disaster Prevention Research Institute, Kyoto University B, 46: 263-273 (in Japanese).

Ishigaki, T., Toda, K., Baba, Y., et al., 2005. Experimental study on evacuation from underground space by using real size models. Annuals of Disaster Prevention Research Institute, Kyoto University B, 48:639-646 (in Japanese).

Ishigaki, T., Kawanaka, R., Onishi, Y., et al., 2009. Assessment of safety on evacuating route during underground flooding. Advances in Water Resources and Hydraulic Engineering, 1-6:141-146. [doi:10.1007/978-3-540-89465-0 27]

Jiang, L.J., Shao, W.Y., Zhu, D.Z., et al., 2014. Forces on surface-piercing vertical circular cylinder groups on flooding staircase. Journal of Fluids and Structures, 46:17-28. [doi:10.1016/j.jfluidstructs.2013.12.011]

Kositgittiwong, D., Chinnarasri, C., Julien, P.Y., 2013. Numerical simulation of flow velocity profiles along a stepped spillway. Proceedings of the Institution of $\mathrm{Me}$ chanical Engineers, Part E: Journal of Process Mechanical Engineering, 227(4):327-335. [doi:10.1177/ 0954408912472172]

Kotani, K., Ishigaki, T., Suzuki, S., et al., 2012. Evaluation for emergency escape during stair climbing in a simulated flood evacuation. Network of Ergonomics Societies Conference (SEANES), Southeast Asian, IEEE, p.1-5. [doi:10.1109/SEANES.2012.6299592]

Launder, B.E., Spalding, D., 1974. The numerical computation of turbulent flows. Computer Methods in Applied Mechanics and Engineering, 3(2):269-289. [doi:10.1016/ 0045-7825(74)90029-2]

MOHURD (Ministry of Housing and Urban-rural Development of the People's Republic of China), 2005. Code for Design of Civil Buildings. Chinese Architecture and Building Press, Beijing (in Chinese).

Ohtsu, I., Yasuda, Y., Takahashi, M., 2004. Flow characteristics of skimming flows in stepped channels. Journal of Hydraulic Engineering, 130(9):860-869. [doi:10.1061/ (ASCE)0733-9429(2004)130:9(860)]
Qian, Z., Hu, X., Huai, W., et al., 2009. Numerical simulation and analysis of water flow over stepped spillways. Science in China Series E: Technological Sciences, 52(7): 1958-1965. [doi:10.1007/s11431-009- 0127-z]

Relvas, A.T., Pinheiro, A.N., 2011. Velocity distribution and energy dissipation along stepped chutes lined with wedge-shaped concrete blocks. Journal of Hydraulic Engineering, 137(4):423-431. [doi:10.1061/(ASCE)HY. 1943-7900.0000318]

Salim, S.M., Cheah, S., 2009. Wall Y strategy for dealing with wall-bounded turbulent flows. Proceedings of the International MultiConference of Engineers and Computer Scientists, Hong Kong.

Schubert, J.E., Sanders, B.F., 2012. Building treatments for urban flood inundation models and implications for predictive skill and modeling efficiency. Advances in Water Resources, 41:49-64. [doi:10.1016/j.advwatres.2012.02. 012]

Shao, W.Y., 2010. Critical rainfall intensity for safe evacuation from underground spaces with flood prevention measures. Journal of Zhejiang University-SCIENCE A (Applied Physics \& Engineering), 11(9):668-676. [doi:10.1631/ jzus.A1000137]

Shao, W.Y., Jiang, L.J., Zhang, Y.P., et al., 2014. Hydraulic features of air-water mixture flow on staircase with rest platforms. Journal of Hydraulic Engineering, 140(6): 04014016. [doi:10.1061/(ASCE)HY.1943-7900.0000 872]

Simões, A.L.A., Schulz, H.E., De Melo Porto, R., 2010. Stepped and smooth spillways: resistance effects on stilling basin lengths. Journal of Hydraulic Research, 48(3):329-337. [doi:10.1080/00221686.2010.481853]

Takahashi, M., Ohtsu, I., 2012. Aerated flow characteristics of skimming flow over stepped chutes. Journal of Hydraulic Research, 50(4):427-434. [doi:10.1080/00221686.2012. 702859]

Taylor, J., Lai, K.M., Davies, M., et al., 2011. Flood management: prediction of microbial contamination in large-scale floods in urban environments. Environment International, 37(5):1019-1029. [doi:10.1016/j.envint. 2011.03.015]

Tongkratoke, A., Chinnarasri, C., Pornprommin, A., et al., 2009. Non-linear turbulence models for multiphase recirculating free-surface flow over stepped spillways. International Journal of Computational Fluid Dynamics, 23(5):401-409. [doi:10.1080/10618560902886882]

Yoneyama, N., Toda, K., Aihata, S., et al., 2009. Numerical analysis for evacuation possibility from small underground space in urban flood. Advances in Water Resources and Hydraulic Engineering, p.107-112. [doi:10. 1007/978-3-540-89465-0_21] 


\section{中文概要}

题 目: 基于数值模拟的阶梯水流中行人安全撤离研究

目 的：研究不同形式阶梯水流中被困人员的安全撤离, 为地下空间水侵灾害脆弱性评价及防灾避灾提 供参考。

方 法: 根据试验结果和数值模型的相关理论构建数值模 型, 验证数值模拟阶梯水流流场的可靠性和合理 性, 并基于数值模型的灵活性和可变性, 模拟休
息平台、阶梯坡度和阶梯形态对水流流场的影响， 据此对有无休息平台、不同阶梯坡度和不同阶梯 形态下阶梯水流流态、流速分布以及对被困人员 的安全撤离的影响进行深入分析。

结 论：中间休息平台的存在增加了被困人员撤离的风 险; 阶梯坡度对阶梯上水流的水力特性影响很 小; $\mathrm{L}$ 型阶梯中间休息平台有利于减小平台下游 撤离风险, 被困人员可以优先选择 $\mathrm{L}$ 型阶梯或者 不含休息平台的直线型阶梯撤离。

关键词: 阶梯; 休息平台; 水侵灾害; 逃生; 数值模拟 